\title{
Impact Compressive Failure of a Unidirectional Carbon/Epoxy Composite: Effect of Loading Directions
}

\author{
T. Yokoyama, a and K. Nakai ${ }^{2, b}$ \\ ${ }^{1,2}$ Okayama University of Science, Okayama 700-0005, Japan \\ ayokoyama@mech.ous.ac.jp, ${ }^{b}$ nakai@mech.ous.ac.jp
}

\section{Keywords: Composite, Hopkinson bar, Impact failure, Loading direction, Strain rate}

\begin{abstract}
The impact compressive failure behaviour of a unidirectional T700/2521 carbon/epoxy composite in three principal material directions is investigated in the conventional split Hopkinson pressure bar. Two different types of specimens with square cross sections are machined from the composite in the plane of the laminate. The uniaxial compressive stress-strain curves up to failure at quasi-static and intermediate strain rates are measured on an Instron testing machine. It is demonstrated that the ultimate compressive strength (or maximum stress) increases slightly, while the ultimate compressive strain (or failure strain) decreases marginally with strain rate in the range of $10^{-3}$ to $10^{3} / \mathrm{s}$ in all three directions. Dominant failure mechanisms are found to significantly vary with strain rate and loading directions along three principal material axes.
\end{abstract}

\section{Introduction}

Compressive failure is a design limiting feature of composite materials, since the compressive strength is much lower that the tensile one. The applications of composite materials involve dynamic loading during their service life. It is, therefore, essential to characterize their compressive strength under impact loading as well as static loading. Compression testing of composite materials is one of the most difficult types of testing because of the tendency for premature failure due to end-crushing or global buckling. Although many techniques for static compression testing of composite materials are currently available (e.g., see [1]), there have been no standard impact compression test methods. The split Hopkinon pressure bar (SHPB), originally developed by Kolsky [2], has widely been used and modified to measure the dynamic compressive properties of engineering materials. More recently, the SHPB has often been applied to characterize the dynamic behavior of various composites under compressive, tensile and shear loading conditions (e.g., see a review [3]). Experimental studies related to the impact compressive failure of unidrectional reinforced composites in three principal material axes are quite limited $[4,5]$.

The objective of the present work is to examine the effects of strain rate and loading directions along the three principal material axes on the compressive failure behavior of a unidirectional (or UD) carbon/epoxy composite. The high strain-rate tests were performed in the standard SHPB. The quasi-static and intermediate strain-rate tests were conducted on an Instron testing machine. Two different types of specimens with square cross sections were used in place of the more traditional cylindrical ones due to lower machinability of UD composite laminates. Different failure mechanisms in the three principal material axes under static and impact compressive loading were discussed. The present study provides important new data for the design of composite structures subjected to high strain-rate loading.

\section{Experimental Procedure}

Test Composite and Specimen Preparation. A 42-ply UD T700/2521carbon/epoxy composite laminate with a nominal thickness of $10.04 \mathrm{~mm}$ was chosen for testing. The laminate was prepared from pre-impregnated tapes each of size $500 \times 500 \mathrm{~mm}^{2}$ and processed in a heat press., i.e., the laminate was heated at a rate of about $2{ }^{\circ} \mathrm{C} / \mathrm{min}$ to a temperature of $125{ }^{\circ} \mathrm{C}$ held for $1 \mathrm{hr}$ at this 
temperature under a pressure of $0.98 \mathrm{MPa}$ and then cooled. The types of reinforcing fiber, matrix resin and fiber volume fraction are given in Table1. The longitudinal (or fiber) and in-plane transverse directions are, respectively, represented by 1 and 2, and the through-thickness direction is represented by 3 (see Fig. 1). Compression loading was applied in the respective directions. The cylindrical geometry has been commonly used in the standard compression tests (see, e.g., ASTM E8 [6]). However, the cylindrical specimens are not machinable from the UD carbon/epoxy composite laminate, except along the 3-direction, because the interlaminar and in-plane shear strengths are extremely low. It is, therefore, decided to use square specimens with a length of 16 $\mathrm{mm}$ and a length/width ratio $=2$ as specified in the ASTM D695 [7] in the quasi-static and intermediate strain-rate tests (see Table 2). Except in the 1-direction tests, cubic specimens with a nominal size of $8 \mathrm{~mm}$ were used in the impact tests by the SHPB. The specimen's ends were carefully polished to ensure smooth surfaces.

Table 1 Type of reinforcing fiber and matrix resin used in UD carbon/epoxy composite

\begin{tabular}{c|c}
\hline & Unidirectional carbon/epoxy \\
\hline Fiber & T700 (Torayca) \\
\hline Matrix resin & Epoxy \#2521 \\
\hline Fiber volume ratio $\mathrm{V}_{\mathrm{f}}$ & 0.65 \\
\hline
\end{tabular}

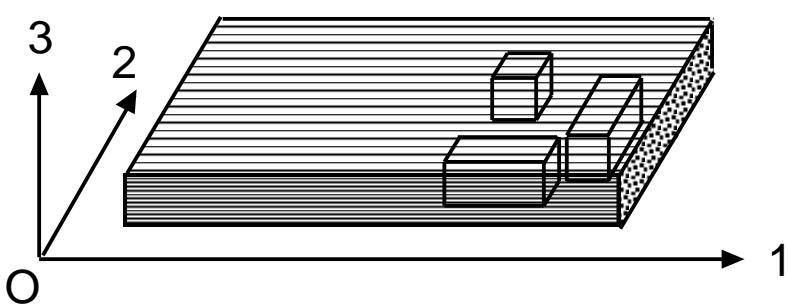

Fig. 1 Three principal directions of UD carbon/epoxy composite (nominal thickness $=10.04 \mathrm{~mm}$ )

Quasi-static and Intermediate Strain-Rate Testing. Quasi-static and intermediate strain-rate compression tests were conduced on $16 \mathrm{~mm}$ long square specimens using the Instron testing machine at two different crosshead velocities of $1 \mathrm{~mm} / \mathrm{min}$ and $100 \mathrm{~mm} / \mathrm{min}$. Both ends of the specimen were lubricated with molybdenum disulfide $\left(\mathrm{MoS}_{2}\right)$ to minimize frictional effects between the specimen and the loading anvils. Only in the 1-direction tests, Inconel rings [8, 9] (see left of Fig. 2), consisting of a $3 \mathrm{~mm}$ thick circular plate with a diameter of $30 \mathrm{~mm}$ and a $8.0 \mathrm{~mm}$ square cutout in the center, were attached at both ends of the specimen to prevent premature kink band formation or longitudinal splitting near the specimen ends. In the 3-direction tests, square specimens constructed by stacking two cubic specimens after aligning them in the fiber direction were used, because the specimen's length in the 3-direction is limited by the thickness of the laminate.

Table 2 Geometries of compression specimens used

\begin{tabular}{l|c|c}
\hline \multirow{2}{*}{ Loading direction } & \multicolumn{2}{|c}{ Specimen dimensions } \\
\cline { 2 - 3 } & Static/ Intermediate & Impact \\
\hline 1-direction & $8 \times 8 \times 16^{*}$ & $8 \times 8 \times 16$ \\
\hline 2-direction & $8 \times 8 \times 16$ & $8 \times 8 \times 8$ (Cubic) \\
\hline 3-direction & $8 \times 8 \times 16$ (Stacked) & $8 \times 8 \times 8$ (Cubic) \\
\hline
\end{tabular}

$*$ Width $\times$ Thickness $\times$ Length $\left(\mathrm{mm}^{3}\right)$

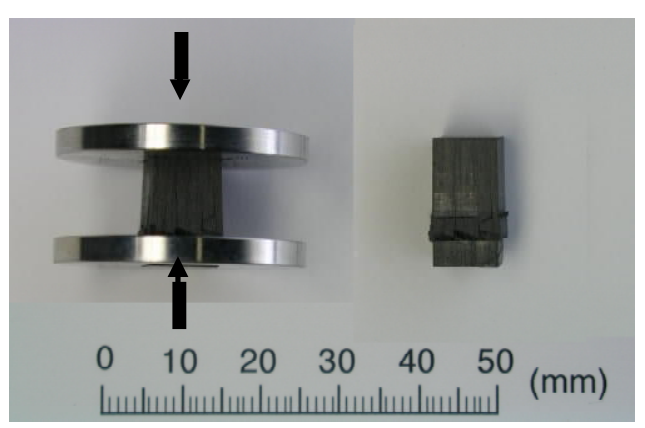

Fig. 2 1- direction specimen at both ends of which are attached with Inconel rings and failed specimen due to kinking band formation. Arrows indicate loading direction.

\section{SHPB Set-up and Data Analysis}

A schematic diagram of the conventional SHPB set-up is shown in Fig. 3. The set-up consists principally of a steel striker bar, a gun barrel, two steel Hopkinson bars and associated recording 
system (not shown). The specimen was sandwiched between the two Hopkinson bars. Both ends of the specimen were also lubricated with molybdenum disulfide to reduce the interfacial friction. Details of the test procedure are given elsewhere [10].

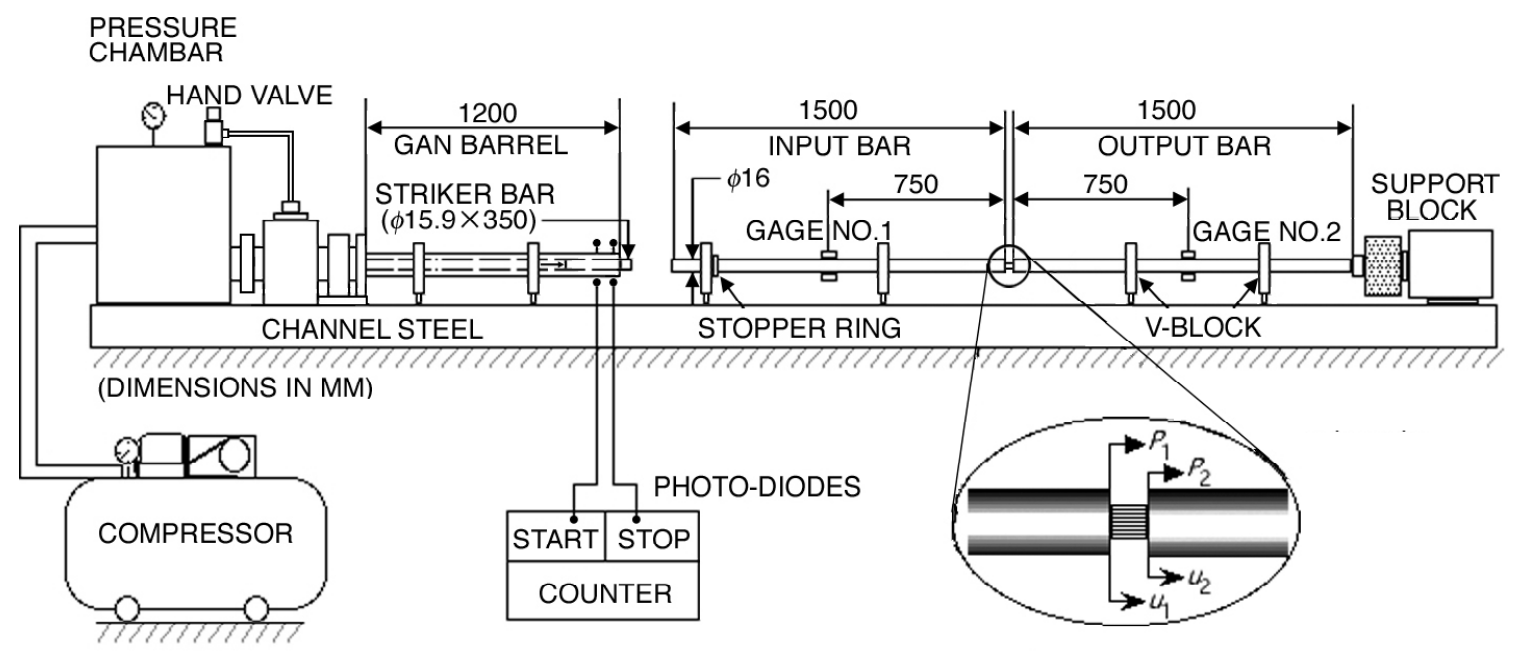

Fig. 3 Schematic diagram of conventional SHPB set-up (recording system not shown)

By applying the elementary theory of elastic wave propagation, we can determine the average nominal strain $\varepsilon(t)$, strain rate $\dot{\varepsilon}(t)$ and stress $\sigma(t)$ in the specimen from the SHPB test records as [11] (where subscripts 1 and 2 denote the left and right interfaces, see, the insert in Fig. 3)

$$
\begin{aligned}
& \varepsilon(t)=\frac{u_{1}(t)-u_{2}(t)}{h}=\frac{2 c_{\mathrm{o}}}{h} \int_{0}^{t}\left\{\varepsilon_{i}\left(t^{\prime}\right)-\varepsilon_{t}\left(t^{\prime}\right)\right\} \mathrm{d} t^{\prime} \\
& \dot{\varepsilon}(t)=\frac{\dot{u}_{1}(t)-\dot{u}_{2}(t)}{h}=\frac{2 c_{\mathrm{o}}}{h}\left\{\varepsilon_{i}(t)-\varepsilon_{t}(t)\right\} \\
& \sigma(t)=\frac{P_{2}(t)}{A_{\mathrm{S}}}=\frac{A E}{A_{\mathrm{S}}} \varepsilon_{t}(t)
\end{aligned}
$$

Here $u_{1}, u_{2}$ and $P_{1}, P_{2}$ are the displacements and the axial forces on both ends of the specimen; $E, A$ and $c_{\mathrm{o}}$ are, respectively; Young's modulus $(=209 \mathrm{GPa})$, the cross-sectional area and the longitudinal elastic wave velocity $(=5205 \mathrm{~m} / \mathrm{s})$ in the Hopkinson bars; $h$ and $A_{\mathrm{s}}$ are the length and cross-sectional area $\left(=64 \mathrm{~mm}^{2}\right)$ of the specimen; $t$ is the time from the start of the strain pulse. Eqs. 1 to 3 are derived based on the assumption of dynamic stress equilibrium across the specimen, which can be expressed as

$$
\sigma_{1}(t)=\sigma_{2}(t)
$$

where

$$
\sigma_{1}(t)=\frac{P_{1}(t)}{A_{s}}=\frac{A E}{A_{s}}\left[\varepsilon_{i}(t)-\varepsilon_{r}(t)\right], \quad \sigma_{2}(t)=\frac{P_{2}(t)}{A_{s}}=\frac{A E}{A_{s}} \varepsilon_{t}(t)
$$

Eliminating time $t$ through Eqs. 1 to 3 yields the nominal compressive stress-strain and strain rate-strain relations for the specimen. Note that the stress and strain are assumed positive in compression. 


\section{Results and Discussion}

Impact Testing. A number of the SHPB tests were carried out at room temperature. Figure 4 gives typical oscilloscope traces from the 1-direction SHPB test on the $16 \mathrm{~mm}$ long square specimen. Figure 5 shows the resulting axial stress histories at the front and back ends of the specimen. An early dynamic stress equilibrim, Eq. 4, is nearly achieved in the specimen until just after a peak stress of $875 \mathrm{MPa}$. Failure initiation occurs at the peak stress (corresponding to the ultimate compressive strength designated as $\sigma_{\mathrm{C}}$ ) at about $55 \mu \mathrm{s}$ and, hence, beyond this point dynamic equilibrium conditions are not valid. This does not affect the accurate determination of $\sigma_{\mathrm{C}}$ at all. Figure 6 depicts the resulting compressive stress-strain and strain rate-strain curves for the 1-direction specimen. Note that there is an abrupt increase in the strain rate at point $\mathrm{X}$ on the stress-strain curve, corresponding to the failure initiation. After the peak stress, a residual stress of nearly $200 \mathrm{MPa}$ is visible. This suggests that the sections of the axially split specimen are still able to carry a compressive load.

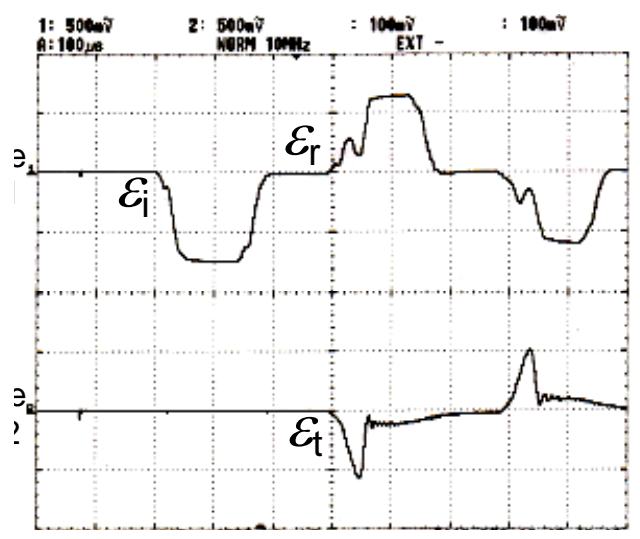

Sweep rate: $100 \mu \mathrm{s} / \mathrm{div}$

Vertical sensitivity:

Upper trace: $500 \mathrm{mV} / \mathrm{div}(1140 \mu \varepsilon / \mathrm{div})$

Lower trace: $500 \mathrm{mV} / \mathrm{div}(1127 \mu \varepsilon / \mathrm{div})$

Fig. 4 Oscilloscope records from 1-direction SHPB test on $16 \mathrm{~mm}$ long square specimen

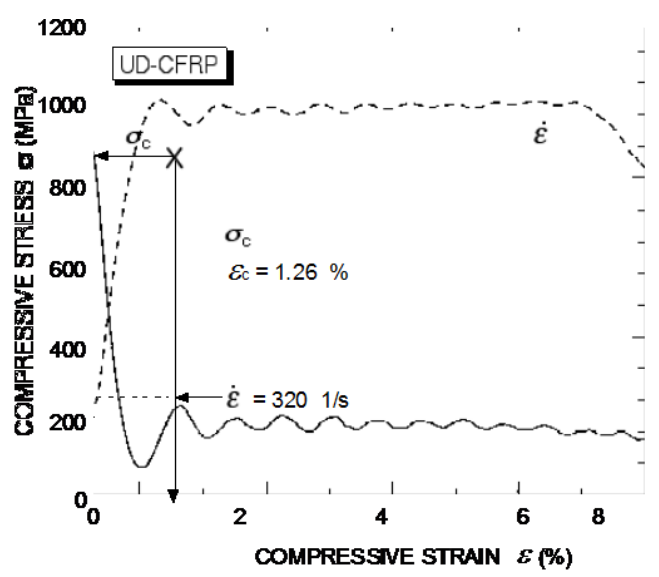

1500

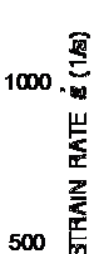

$\stackrel{0}{10}$

Fig. 6 Dynamic compressive stress-strain and strain rate-strain relations in 1- direction

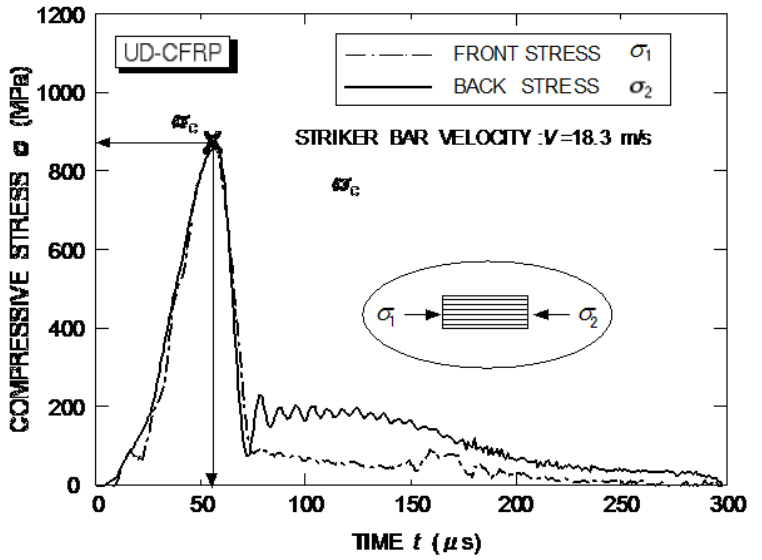

Fig. 5 Dynamic compressive stress histories at both ends of $16 \mathrm{~mm}$ long square specimen

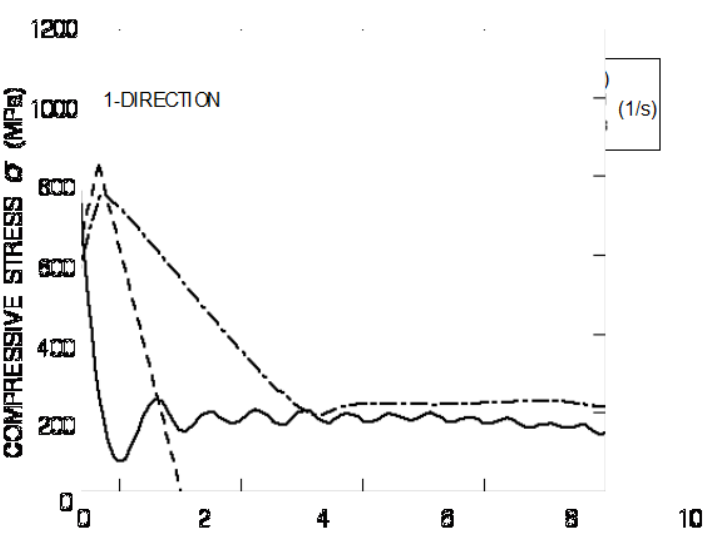

Fig. 7. Compressive stress-strain curves in 1direction at three different strain rates 


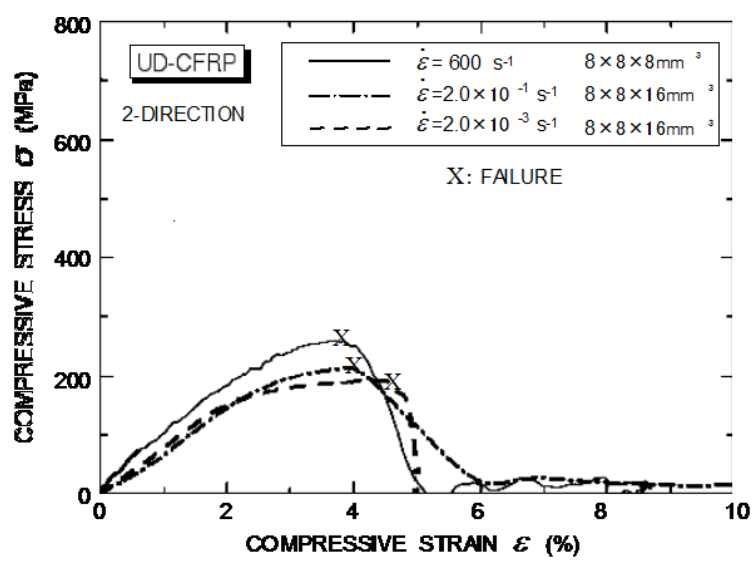

Fig. 8 Compressive stress-strain curves in 2direction at three different strain rates

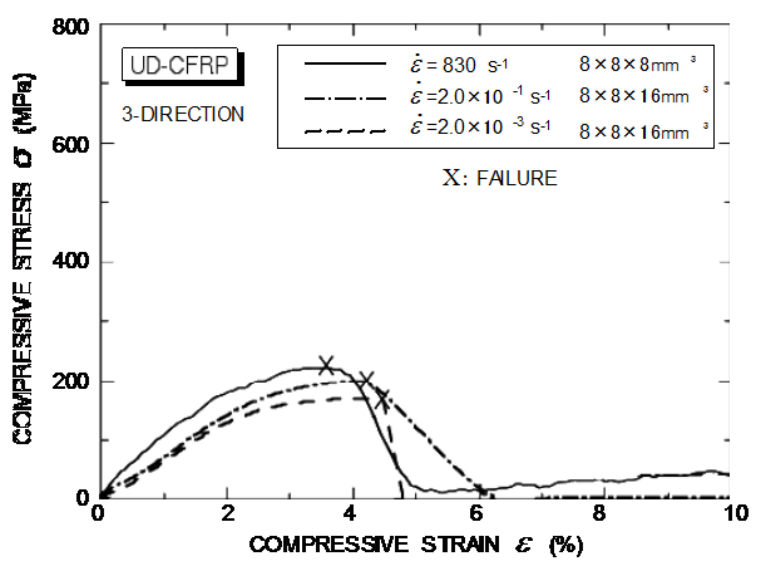

Fig. 9 Compressive stress-strain curves in 3- direction at three different strain rates

The 1-direction SHPB tests were also conducted on the cubic specimens $\left(8 \times 8 \times 8 \mathrm{~mm}^{3}\right)$. Although the failure mode was the same as that in the $16 \mathrm{~mm}$ long square specimens, the significant reductions in compressive modulus and strength were observed. This may be caused by micro-bukling arising at local regions of fiber misalignment (e.g., see [12]), which is usually considered to be the mechanisms whereby longitudinal compressive failure is initiated in the UD reinforced composites. Micro-bucking [13] associated with the 1-direction tests is very sensitive to the specimen's length/width ratio.

The uniaxial compressive stress-strain curves in the 1-, 2- and 3-directions at three different strain rates are, respectively, shown in Figs. 7 to 9. It is observed that each of initial moduli increases with increasing strain rate, which is quite consistent with the SHPB test results for a different UD carbon/epoxy laminate by $\mathrm{Li}$ and Lambros [4]. This may be due to the viscoelastic nature of the epoxy resin matrix itself [14]. The 2- and 3-directions have similar stress-strain properties. As anticipated, the flow stress level in the 1-direction is much higher than that in the 2- and 3directions. In order to describe the effects of strain rate and loading directions on the compressive properties, the ultimate compressive strength and strain (or failure strain), and the absorbed energy up to failure are plotted against a newly defined strain rate at failure $\dot{\varepsilon}_{\mathrm{f}}$ in Figs. 10 to 12, where that is expressed as $\dot{\varepsilon}_{\mathrm{f}}=\varepsilon_{\mathrm{C}} / t_{\mathrm{f}}$ ( $t_{\mathrm{f}}$ : failure initiation time), considering almost linear elastic behavior of the composite before failure. In an attempt to further quantify the rate dependence of the compressive properties, a straight line was fitted to a number of data points in Figs. 10 to 12 using a linear regression analysis. This leads to the following three relations:

$$
\begin{aligned}
& \log \sigma_{\mathrm{c}}=m_{\sigma} \log \dot{\varepsilon}_{\mathrm{f}}+\log \sigma_{0} \\
& \log \varepsilon_{\mathrm{c}}=m_{\varepsilon} \log \dot{\varepsilon}_{\mathrm{f}}+\log \varepsilon_{0} \\
& \log U_{\mathrm{c}}=m_{U} \log \dot{\varepsilon}_{\mathrm{f}}+\log U_{0}
\end{aligned}
$$

where each $m$ is a strain-rate sensitivity parameter, and $\sigma_{0}, \varepsilon_{0}$ and $U_{0}$ are material parameters. The respective parameters in Eqs. 5 to 7 are summarized in Table 3. It is clearly seen that the ultimate compressive strength $\sigma_{\mathrm{c}}$ exhibits the positive strain-rate sensitivity in all three directions, whereas the failure strain $\varepsilon_{\mathrm{c}}$ and the absorbed energy $U_{\mathrm{c}}$ exhibit the negative one, except for $U_{\mathrm{c}}$ in the 1-direction. Three fitted curves are shown as the solid lines in each of Figs. 10 to 12. 


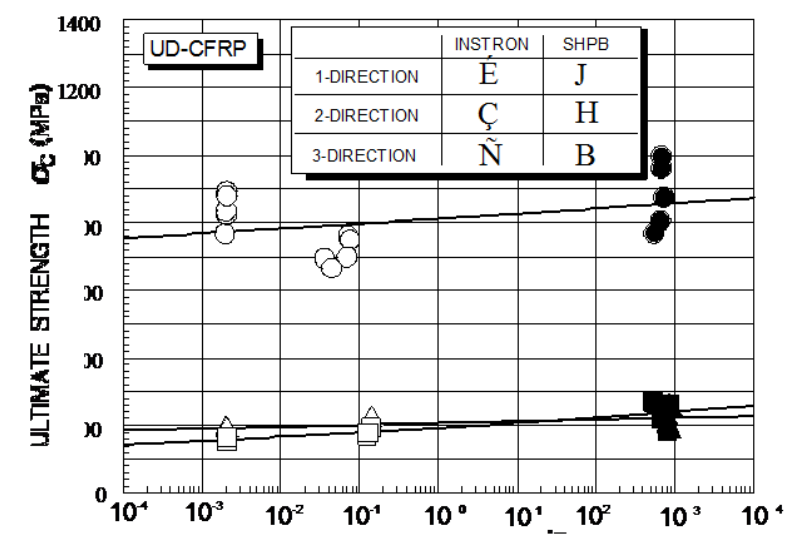

Fig. 10 Effect of strain rate at failure on ultimate strength in three different directions

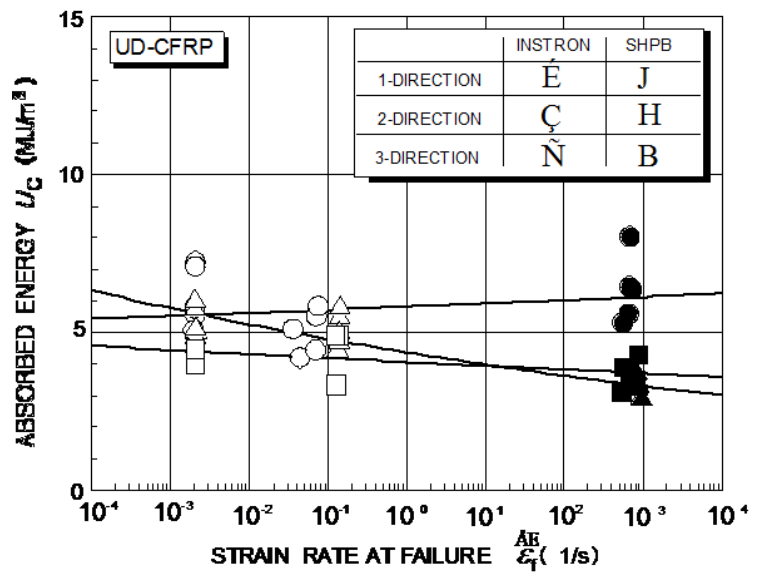

Fig. 12 Effect of strain rate at failure on absorbed energy up to failure in three different directions

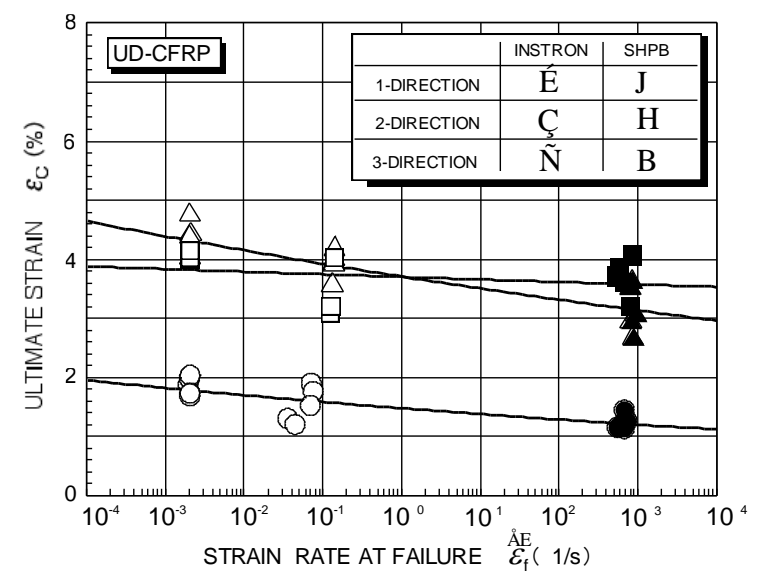

Fig. 11 Effect of strain rate at failure on ultimate strain in three different directions

Table 3 Parameters of fitted curves for rate dependence of compressive properties of UD carbon/epoxy composite

$$
\sigma_{\mathrm{C}}=\sigma_{0} \dot{\varepsilon}_{\mathrm{f}}^{m_{\sigma}} ; \varepsilon_{\mathrm{C}}=\varepsilon_{0} \dot{\varepsilon}_{\mathrm{f}}^{m_{\varepsilon}} ; U_{\mathrm{C}}=U_{0} \dot{\varepsilon}_{\mathrm{f}}^{m_{U}}
$$

\begin{tabular}{c|c|c|c|c|c|c}
\hline \multirow{2}{*}{$\begin{array}{c}\text { Loading } \\
\text { direction }\end{array}$} & \multicolumn{2}{|c|}{$\sigma_{\mathrm{C}}(\mathrm{MPa})$} & \multicolumn{2}{c|}{$\varepsilon_{\mathrm{C}}(\%)$} & \multicolumn{2}{c}{$U_{\mathrm{C}}\left(\mathrm{MJ} / \mathrm{m}^{3}\right)$} \\
\cline { 2 - 7 } & $\begin{array}{c}\sigma_{0} \\
(\mathrm{MPa})\end{array}$ & $m_{\sigma}$ & $\begin{array}{c}\varepsilon_{0} \\
(\%)\end{array}$ & $m_{\varepsilon}$ & $\begin{array}{c}U_{0} \\
\left(\mathrm{MJ} / \mathrm{m}^{3}\right)\end{array}$ & $m_{U}$ \\
\hline 1-d & 814 & $7.9 \times 10^{-3}$ & 1.5 & $-30 \times 10^{-3}$ & 5.8 & $7.5 \times 10^{-3}$ \\
\hline 2-d & 209 & $10.8 \times 10^{-3}$ & 3.7 & $-24.3 \times 10^{-3}$ & 4.4 & $-40 \times 10^{-3}$ \\
\hline 3-d & 195 & $31.6 \times 10^{-3}$ & 3.7 & $-5.1 \times 10^{-3}$ & 4.1 & $-12.9 \times 10^{-3}$ \\
\hline
\end{tabular}

Failure Modes. The failure modes in the 1-, 2- and 3- direction specimens under quasi-static and impact compressive loading are given in Fig. 13. Visual inspections of the static specimens (each left) reveal that in the 1-direction, the failure occurred mainly by kinking and fiber micro-buckling, while in the 2-and 3-directions, the failure modes are basically shear failure and transverse matrix cracking. In the SHPB tests, the specimens are usually subjected to repeated compressive loading by the elastic waves traveling back and forth in the input bar after failure initiation. Consequently, the specimens are catastrophically disintegrated into several small pieces. The separate pieces are held together to show the actual dynamic failure modes in the impact specimens. Impact failure appearance (each right) suggests that the failure modes are greatly affected by the strain rate as well as the loading directions. That is, in the 1-direction, longitudinal splitting results from failure at the fiber/matrix interface at a specific location, which then propagates through the entire length of the interface, while in the 2-direction, interply delamination and transverse matrix cracking are the dominant failure modes. In the 3-direction, the failure initiated at the loading (left) face of the specimen and coalesced at the mid-height of the specimen. 
LOADING DIRECTION

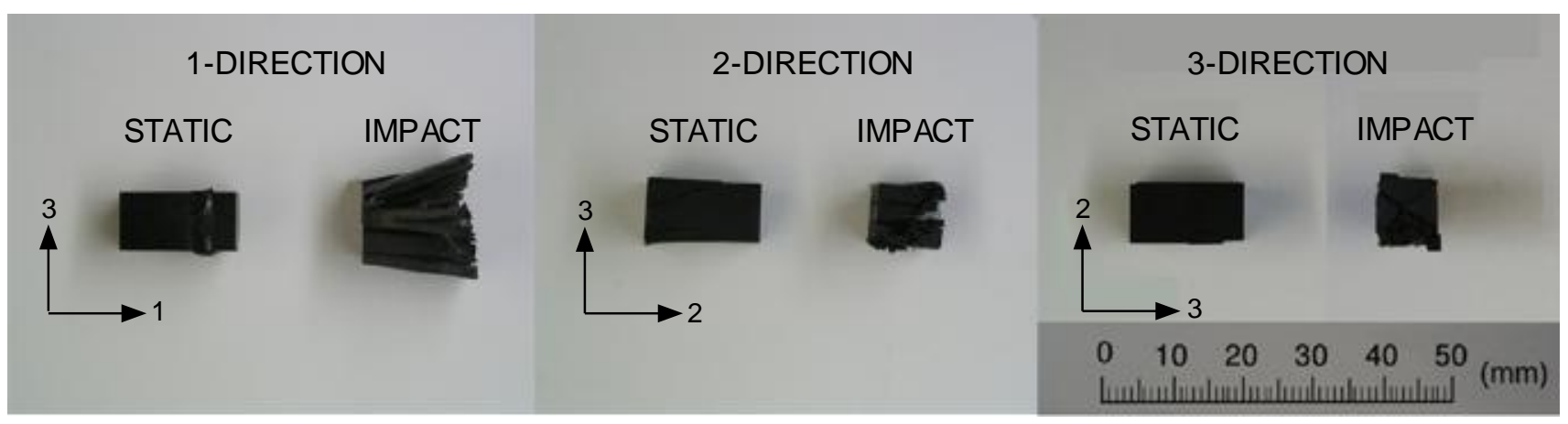

Fig. 13 Different failure modes in static and impact specimens under 1, 2 and 3-directions loading. Each left face of impact specimens corresponds to loading face of input bar.

\section{Conclusions}

The effects of varying strain rates from $10^{-3}$ to nearly $10^{3} / \mathrm{s}$ and loading directions along the three principle material axes on the compressive failure behavior of the UD T700/2521carbon/epoxy composite have been studied using both the SHPB and the Instron testing machine. From the experimental investigation, we can make the following conclusions:

1.The ultimate compressive strength in the 1-direction is nearly four times as high as that in the 2and 3 - directions at any strain rate.

2.The ultimate compressive strength increases slightly, while the ultimate compressive strain (or failure strain) decreases marginally with increasing strain rate in all three directions.

3.The absorbed energy up to failure in the 1-direction increases slightly, while that in the other two directions decreases marginally with increasing strain rate.

4.The failure modes are strongly affected by strain rate as well as loading directions.

\section{References}

[1] ASTM D3410-87: ASTM Standards and Literature References for Composite Materials, 2nd Ed., ASTM (1990), p. 38.

[2] H. Kolsky: Proc. Phys. Soc., Vol. B62 (1949), 676-700.

[3] R.L. Sierakowski: Applied Mechanics Review, Vol. 50, No. 12, Part 1 (1997), 741-761.

[4] Z. Li and J. Lambros: Compos. Sci. Technol., Vol. 59 (1999), 1097-1107.

[5] M.V. Hosur, J. Alexander, U.K. Vaidya and S. Jeelani: Compos. Struct., Vol. 52 (2001), 405-417.

[6] ASTM E9-89: Annual Book of ASTM Standards, Vol. 03.01, ASTM (1995), p. 98.

[7] ASTM D695-89: ASTM Standards and Literature References for Composite Materials, 2nd Ed., $\operatorname{ASTM}(1990)$, p. 275.

[8] J. Lankford: Advanced Composites Materials, Vol. 19 (1991), 553-563.

[9] J. Yuan, N. Takeda and A.M. Waas: Sci. Engng Compos. Mater. Vol.9, No.1 (2000), 1-9.

[10] T. Yokoyama: Applied Mechanics and Materials, Vol. 1, No. 2 (2004), 11-16.

[11] U.S. Lindholm: J. Mech. Phys. Solids, Vol. 12 (1964), 317-335.

[12] J.G. Häberle and F.L. Matthews: J. Compos. Mater., Vol.28, No.17 (1994), 1618-1639.

[13] C.T. Sun and A.W. Jun: Compos. Sci. Technol., Vol. 52 (1994), 577-587.

[14] T.E. Tay, H.G. Ang and V.P.W. Shim: Compos. Struct., Vol. 33 (1995), 201-210. 